\title{
ENVELHECIMENTO E COVID-19: ASSOCIAÇÃO ENTRE COMORBIDADES E GRAVIDADE DA DOENÇA
}

Kimberly Mayara Gouveia Bezerra; Universidade Federal de Pernambuco - UFPE; kimberly.gouveia@ufpe.br

Crislayne Maria Berto; Universidade Federal de Pernambuco - UFPE; crislayne.berto@ufpe.br Fernando Arthur Alves da Silva; Universidade Federal de Pernambuco - UFPE; fernando.arthur@ufpe.br Leiliane Moraes dos Santos Silva; Universidade Federal de Pernambuco - UFPE; leiliane.moraes@ufpe.br Ana Paula de Oliveira Marques; Universidade Federal de Pernambuco - UFPE; ana.marques@ufpe.br

\section{RESUMO}

Introdução: Atualmente, tem-se constatado o alto número de idosos hospitalizados por COVID-19, os quais geralmente apresentam condições clínicas subjacentes, com o aumento da idade sendo associado à gravidade clínica, incluindo letalidade. Objetivo: Investigar a associação entre comorbidades e gravidade da COVID-19 em idosos. Métodos: Realizou-se uma revisão integrativa nas bases de dados Literatura Internacional em Ciências da Saúde (MEDLINE), Scientific Electronic Library Online (SciELO), Centro Latino-Americano e do Caribe de Informação em Ciências da Saúde (LILACS), Pubmed e Web of Science, utilizando a combinação dos descritores "comorbidity“, "risk factors", "COVID-19" e "elderly". Foram encontrados 270 artigos no total. Destes, 31 foram pré-selecionados e, após aplicação dos critérios de elegibilidade, restaram 12 artigos, os quais compuseram esta revisão. Resultados: Os idosos somam 20,5\% dos casos graves de COVID-19. A presença de comorbidade aumenta a atividade do gene ECA2, o qual é responsável pela expressão da proteína transmembrana Enzima Conversora de Angiotensina 2 (ECA2), relacionada com a infecção celular pelo vírus SARS-CoV-2. Além disso, os estudos constataram que diagnósticos preexistentes de demência, diabetes tipo 2, hipertensão arterial, Doença Pulmonar Obstrutiva Crônica (DPOC), doenças cardíacas e depressão em idosos são estatisticamente significativas para o desenvolvimento da forma mais grave da COVID-19 e para mortalidade dessa população. Outro ponto interessante é que a Doença Renal Crônica (DRC) contribuiu principalmente para a morte. Conclusão: A presença de comorbidades na população idosa com COVID-19 está relacionada a maior gravidade e pior prognóstico da doença.

Palavras-chave: COVID-19; SARS-Cov-2; Idoso; Comorbidade. 